\title{
ИНЪЕКЦИОННЫЙ КОЛЛАГЕН В КОРРЕКЦИИ ВОЗРАСТНЫХ ИЗМЕНЕНИЙ КОЖИ: ЭКСПЕРИМЕНТАЛЬНО-КЛИНИЧЕСКИЕ ПАРАЛЛЕЛИ
}

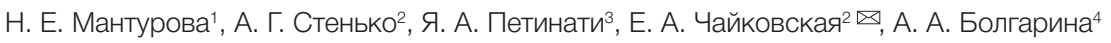

1 Российский национальный исследовательский медицинский университет имени Н. И. Пирогова, Москва, Россия

${ }^{2} \mathrm{AO}$ «Институт пластической хирургии и косметологии», Москва, Россия

${ }^{3}$ Научно-исследовательский институт медицины труда имени академика Н. Ф. Измерова, Москва, Россия

${ }^{4} \mathrm{OОО} \mathrm{«Ниармедик} \mathrm{Плюс»,} \mathrm{Москва,} \mathrm{Россия}$

Возрастные изменения лица в виде морщин, дряблости кожи во многом связаны со структурными изменениями дермы, в том числе с фрагментацией и дезорганизацией коллагеновых волокон. Различные методы косметологической коррекции направлены на активизацию неоколлагенеза и ремоделирование дермы. С этой точки зрения логичным видится проведение внутрикожных инъекций препаратов экзогенного коллагена. Целью исследования было изучить эффективность и безопасность применения коллагенового комплекса Коллост 7\% в коррекции возрастных изменений кожи лица, а также уточнить возможные механизмы развития эффекта омоложения кожи после курса внутрикожных инъекций. В исследование были включены 34 участницы, завершили его 30 участниц. Оценка комплекса показателей возрастных изменений кожи с помощью клинических шкал продемонстрировала выраженное улучшение качества кожи и разглаживание ее рельефа, особенно в области локализации тонких морщин. После завершения курса лечения достоверно повысилась эластичность кожи лица, что вкупе с изменениями, выявленными при УЗ-сканировании (повышение толщины дермы и ее акустической плотности), косвенно свидетельствует о структурной перестройке кожи с накоплением белковых волокнистых структур. Полученные результаты позволяют проводить параллели с данными экспериментальных исследований, показывающими активизацию неоколлагенеза в коже лабораторных животных после курсового введения геля Коллост 7\%. Серьезных нежелательных явлений при проведении исследования не выявлено. Курсовое внутрикожное введение коллагена можно рекомендовать как процедуру эстетической коррекции, а также в качестве профилактики развития атрофических процессов, которые существенно сказываются на внешнем виде и здоровье кожи.

Ключевые слова: старение кожи, омоложение кожи, инъекции коллагена

Благодарности: авторы благодарят компанию ООО «Ниармедик Плюс» (Москва) за поддержку клинического наблюдательного исследования, а также благодарят Наталью Индилову, Галину Софинскую, Евгению Иконникову — врачей-исследователей АО «Институт пластической хирургии и косметологии»; Ольгу Бондареву, Олесю Сидорову — врачей НПЦ «Космопродтест» за помощь в проведении исследования.

Информация о вкладе авторов: Н. Е. Мантурова - планирование исследования и интерпретация данных; А. Г. Стенько, Я. А. Петинати - подбор участников, проведение исследования, интерпретация данных; Е. А. Чайковская - планирование исследования, сбор и интерпретация данных, подготовка рукописи; А. А. Болгарина — анализ литературы, планирование исследования.

Соблюдение этических стандартов: исследование одобрено этическим комитетом Общества эстетической медицины (протокол № 2 от 7 сентября 2017 г.). Регистрационный номер на портале www.ClinicalTrials.gov — NCT03677258.

$\triangle$ Для корреспонденции: Екатерина Александровна Чайковская ул. Ольховская, д. 27, г. Москва, 105066; ktchaikovskaya@yandex.ru

Статья получена: 27.09.2018 Статья принята к печати: 25.02.2019 Опубликована онлайн: 09.03.2019

DOI: $10.24075 /$ vrgmu.2019.010

\section{INJECTABLE COLLAGEN IN CORRECTION OF AGE-RELATED SKIN CHANGES: EXPERIMENTAL AND CLINICAL PARALLELS}

Manturova NE${ }^{1}$, Stenko $A G^{2}$, Petinati $Y A^{3}$, Chaikovskaya $E A^{2} \bowtie$, Bolgarina $A A^{4}$

${ }^{1}$ Pirogov Russian National Research Medical University, Moscow, Russia

${ }^{2}$ Institute of plastic surgery and cosmetology, Moscow, Russia

${ }^{3}$ Izmerov Research Institute of Occupational Health, Moscow, Russia

${ }^{4}$ LLC Nearmedic PLUS, Moscow, Russia

To a large extent, age-related facial skin changes, wrinkles and flabbiness, are attributed to the structural alterations in dermis, including of collagen fibers fragmentation and disorganization. There are various cosmetological correction methods that aim to activate neocollagenesis and dermal remodeling. From this perspective, intradermal injections of exogenous collagen preparations seem logical. This study aimed to investigate the efficacy and safety of Collost $7 \%$ collagen complex applied to correct the age-related facial skin changes, as well as clarify the possible mechanisms of skin rejuvenation resulting from a course of intradermal injections. 35 participants entered the study, 30 of them finished it. A set of indicators describing age-related skin changes was assessed with the help of clinical scales; the assessment revealed a pronounced improvement in the quality of the patients' skin, including smoothed relief in the area of localization of fine wrinkles. The therapy resulted in a statistically significant improvement of the skin's elasticity, which, combined with the changes discovered through US scanning (greater dermis thickness and echodensity), is an indirect indication of skin restructuring associated with accumulation of fibrous protein structures. These results allow parallels with the experimental data that shows activation of neocollagenesis in the skin of laboratory animals after a course of Collost $7 \%$ gel. The research revealed no serious adverse events. A course of collagen administered intradermally can be recommended as an aesthetic correction procedure, as well as means of prevention of atrophy that has a significant effect on skin's appearance and health status.

Keywords: skin ageing, skin rejuvenation, collagen injection

Acknowledgements: the authors would like to thank "Nearmedic Plus" (Moscow) for the support of the clinical observational study, as well as Natalya Indilova, Galina Sofinskaya, Evgenia Ikonnikova, medical researchers of the Institute of Plastic Surgery and Cosmetology, and Olga Bondareva and Olesya Sidorova, doctors with Cosmoprodtest SPC, for the assistance they provided in the context of this study.

Author contribution: Manturova NE — research planning and data interpretation; Stenko AG, Petinati YaA — selection of participants, conducting research, data interpretation; Chaikovskaya EA — research planning, data collection and interpretation, manuscript preparation; Bolgarina AA — literature analysis, research planning

Compliance with ethical standards: the study was approved by the Society of Aesthetic Medicine ethical committee (Protocol №2 of September 07, 2017). Registration number at www. ClinicalTrials.gov: NCT03677258.

$\triangle$ Correspondence should be addressed: Ekaterina A. Chaikovskaya Olkhovskaya, 27, Moscow, 105066; ktchaikovskaya@yandex.ru

Received: 27.09.2018 Accepted: 25.02.2019 Published online: 09.03.2019

DOI: $10.24075 / \mathrm{brsmu} .2019 .010$ 
Кожа как орган тела человека выполняет целый ряд функций: барьерную, терморегуляторную, иммунной защиты; продуцирует обширный спектр гормонов. В последние годы самое пристальное внимание уделяется ее социальной функции, ведь «внешний» возраст человека во многом определяется именно внешним видом лица - эстетической картиной, наличием симптомов или следов каких-либо заболеваний. Моложавость и привлекательность лица способствуют установлению и поддержанию социальных контактов, коммуникации, что тем или иным способом сказывается на успешности профессиональной и личной жизни человека, качестве его жизни [1]. Поэтому все аспекты коррекции возрастных изменений кожи лица остаются предметом клинических исследований, в том числе с точки зрения эффективности и безопасности используемых средств и методов.

При определении внешнего возраста прежде всего ориентируются на выраженность на лице морщин и складок [2, 3], напрямую связанных с биомеханическими свойствами кожи [4, 5], которые, в свою очередь, определяются состоянием внеклеточного матрикса дермы - соединительнотканного слоя кожи.

Коллаген является базовым белком любой соединительной ткани, причем половина его общего количества находится именно в поверхностных тканях, составляя около 70\% белков в составе кожи [6]. Основными структурными компонентами дермы являются волокнообразующие коллагены I и III типов, сложная архитектоника волокон которых обеспечивает такие показатели, как прочность, упругость, эластичность кожи, способность к репарации [1, 5, 7, 8]. С возрастом коллагеновый матрикс дермы претерпевает существенные изменения, связанные как с запрограммированными процессами хроностарения, так и с ускоренным старением на фоне заболеваний, изменения гормонального фона, действия агрессивных факторов окружающей среды УФ-излучения, поллютантов, курения, погрешностей питания [1, 9-12]. В проведенных исследованиях показано, что с возрастом количество коллагена в дерме прогрессивно уменьшается - примерно на 20\% каждое десятилетие после достижения женщинами 40 лет [7]. Конкретные данные в разных исследованиях отличаются [13-16]. Но тенденция остается неизменной и связана она с угнетением пролиферативной и синтетической функций фибробластов: по мере старения снижается их общий пул, клетки приобретают «спящий» неактивный фенотип [17]. Параллельно с количественными изменениями меняется и качество коллагеновых волокон: они подвергаются уплотнению за счет формирования дополнительных ковалентных сшивок полипептидных цепей. Подобные структуры становятся более устойчивыми к действию матриксных металлопротеиназ, катаболизирующих белки и обеспечивающих таким образом их обновление. Во внеклеточном матриксе накапливаются хаотично расположенные фрагментированные волокна коллагена, теряющие фокальные контакты с фибробластами. Клетки утрачивают структурно-функциональный контакт с матриксом и приобретают неактивный фенотип $[9,12$, 17-19]. Так формируется порочный круг, закрепляющий структурные изменения кожи, которые и обусловливают формирование характерной клинической картины «возрастного лица». Одним из подтверждений этого тезиса служит тот факт, что у больных системной склеродермией, чья кожа толще и содержит большее количество коллагена, возрастные изменения лица в виде морщин, складок и расширенных пор формируются гораздо позже [20].

Изложенное выше актуализирует необходимость дальнейшего изучения возможностей различных косметологических методик по восстановлению коллагенового каркаса дермы. Наряду с эстетическим аспектом очень важным является восстановление репаративного ресурса кожи: коллаген в форме организованной волокнистой сети участвует в регуляции миграции, пролиферации, дифференциации клеток, их взаимодействии $[8,21]$.

Доказано, что достоверно стимулируют неоколлагенез топические препараты ретиноидов, лазерное воздействие на кожу, а также внутрикожное введение филлеров гелей на основе стабилизированной гиалуроновой кислоты, полимолочной кислоты, частиц гидроксиапатита кальция [22-26]. Во всех случаях задействованы разные механизмы, однако приводят они к единому результату - в областях воздействия формируется плотная волокнистая коллагеновая сеть. С этой же целью активно изучаются такие методы, как внутрикожное введение микрогранул и нитей на основе поликапролактона, активных пептидов, радиочастотное воздействие на кожу, воздействие микрофокусированным ультразвуком, механическая микроперфорация кожи и др. Этиологически обоснованным выглядит и введение непосредственно в дерму инъекционных форм коллагена. История эстетической коллагенотерапии насчитывает уже около 40 лет: в 1981 г. Управление по санитарному надзору за качеством пищевых продуктов и медикаментов (Food and Drug Administration, FDA) зарегистрировало первый инъекционный материал на базе этого вещества. Медицинские изделия на основе коллагена кожи коров являются безопасными и показывают хорошую биосовместимость [27]. Предполагаемые механизмы действия коллагеновых материалов при внутрикожном введении включают в себя как временную гидратацию дермы и оптимизацию свойств внеклеточного матрикса, так и стимулирующие эффекты коротких пептидов (матрикинов), образующихся при биодеградации экзогенного коллагена [8, 28, 29]. Накопление фрагментов белка уже само по себе - по механизму обратной биологической связи - становится стимулятором синтеза белка de novo [30].

В нашей стране разработан, производится и активно применяется в разных областях медицины, включая косметологию, коллагеновый материал в виде стерильного геля - Коллост 7\% и 15\% (ООО «БиоФАРМАХОЛДИНГ»; Россия). В процессе производства коллаген выделяют из шкур крупного рогатого скота и подвергают глубокой очистке от примесей с сохранением нативной волокнистой структуры и свойств белка. Материал зарегистрирован в качестве инъекционного медицинского изделия (ФСР 2008/02112 от 26 февраля 2016 г.). Среди показаний к применению в косметологии - возрастные и атрофические изменения кожи. Внутрикожные инъекции материала способствуют моментальному восстановлению дефицита объема мягких тканей; курс инъекций обеспечивает пролонгированный результат [31, 32]. Перед проведением процедур обязательно выполняется аллергопроба для выявления гиперчувствительности к животному коллагену.

Метаболизм и биохимические эффекты имплантированного в кожу геля Коллост 7\% были детализированы в недавно проведенных экспериментальных исследованиях [21]. После двух внутрикожных инъекций материала лабораторным животным (крысам) в их 
коже в течение всего времени наблюдения (37 дней) отмечалось повышение уровня суммарного коллагена и его растворимой фракции. По мнению исследователей, в течение нескольких следующих за инъекциями дней (2-е и 4-е сут.) повышение уровня коллагена связано с присутствием экзогенного белка, в отдаленные же сроки (21-е и 37-е сут.) наблюдаемая тенденция отражает активизацию неоколлагенеза в коже. Подтверждением данной гипотезы служит и то, что в эти же сроки отмечалось значительное усиление включения в белок кожи меченных радиоизотопом $\mathrm{C}^{14}$ аминокислот. На протяжении семи дней наблюдения фиксировалось повышение коллагенолитической активности кожи, что, по-видимому, было связано с процессом биодеградации чужеродного белка. Выявленные процессы позволяют говорить о том, что экзогенный коллаген с сохраненной нативной структурой, подвергаясь биодеградации, стимулирует синтез собственного белка.

Одной из целей проведенного проспективного наблюдательного исследования «Изучение эффективности и безопасности восстановительного коллагенового комплекса Коллост 7\% в коррекции возрастных изменений кожи лица» было уточнение с использованием неинвазивных методов диагностики возможных механизмов развития эффекта омоложения кожи в течение и после завершения курса внутрикожных инъекций.

\section{ПАЦИЕНТЫ И МЕТОДЫ}

Исследование проводили в период с октября 2017 г. по июнь 2018 г. на базе АО «Институт пластической хирургии и косметологии» и ФГБНУ «Научно-исследовательский институт медицины труда имени академика Н. Ф. Измерова». Были скринированы 34 участницы для последующего проведения курса инъекций материала Коллост; согласно критериям включения/исключения в исследование было включено 30 пациенток.

Критерии включения: женский пол; возраст 35-65 лет; I-III фототипы кожи; признаки возрастных изменений кожи лица; отсутствие хронических заболеваний в стадии декомпенсации; отказ от проведения каких-либо косметологических процедур во время исследования. Критерии исключения: беременность; период лактации; инфекционный процесс; дерматозы; злокачественные новообразования на коже в области предполагаемой коррекции; системные заболевания соединительной ткани с поражением кожи и подкожной клетчатки (системная красная волчанка, гранулема кольцевидная, дискоидная красная волчанка, склеродермия, дерматомиозит и др.); обострение или декомпенсация хронических соматических заболеваний; инфекционные, онкологические заболевания; нарушения свертывания крови, в том числе ятрогенного характера на фоне текущей фармакотерапии; прием изотретиноина в течение предшествующих 6 месяцев; склонность к формированию гипертрофических и келоидных рубцов; прием антигистаминных препаратов, глюкокортикоидов, НПВС, иммунодепрессантов и других лекарственных средств, влияющих на реактивность кожи; гиперчувствительность к компонентам изучаемого медицинского изделия.

Возраст участниц составил 36-64 года (медиана 48,50 лет; 25-й и 75-й процентили - 43,00 и 57,00 лет). Все они были представительницами европеоидной расы с массой тела 52-80 кг и индексом массы тела не более 30. На протяжении всего времени наблюдения участницы поддерживали стабильную массу тела (колебания не более 2 кг) во избежание искажения клинической картины старения лица. У 93,33\% аллергологический анамнез не отягощен; аллергические реакции на местные анестетики отсутствовали у 100\% участниц. Большинство пациенток (24 человека, 80,00\%) было некурящими, все придерживались смешанного режима питания. У подавляющего числа участниц кожа имела нормальную толщину и нормальную чувствительность (повышенная чувствительность отмечалась у $16,67 \%$ участниц). В итоге «усредненный портрет» участницы исследования выглядел следующим образом: женщина около 50 лет со светлой кожей; картиной фотостарения, соответствующей возрасту; с наличием признаков возрастных десормационных изменений лица, что в значительной степени связано с развитием дряблости кожи, т. е. с изменением ее биомеханических свойств.

Программа исследования подразумевала после детального обследования описание общей картины состояния кожи лица по восьми показателям (оцененным при помощи 5-балльной шкалы по Гейниц - AlexiadesArmenakas [33, 34]) с подсчетом интегрального показателя состояния кожи лица, а также оценку степени выраженности морщин в семи областях по 5-балльной валидированной фотошкале MAS (Merz Aesthetic Scale) [35].

C помощью инструментальных методов диагностики проводили:

- измерение эластичности кожи - методом кутометрии (лоб, параорбитальная область, щека); на аппаратах Multi Skin Test Center MC-900 и Cutometer Dual MPA-580 (Courage + Khazaka electronic GmbH; Германия);

- оценку толщины эпидермиса и дермы, акустической плотности дермы - УЗ-сканированием кожи в аналогичных областях лица контрлатерально на аппаратах DUB SkinScanner (Taberna pro medicum; Германия) и DermaScan C-System (Cortex Technology; Дания) с датчиками 20-22 МГц.

Эффективность курса косметологической коррекции оценивали как врачи-исследователи, так и сами участницы с использованием универсальной эстетической шкалы GAIS (Global Aesthetic Improvement Scale) [35].

Документирование результатов проводили с помощью фотосистемы LifeViz (QuantifiCare; Франция), позволяющей получать и анализировать трехмерные изображения лица.

Для оценки безопасности внутрикожных инъекций материала Коллост после каждой процедуры описывали нежелательные явления (немедленные и отсроченные), гипотетически связанные как с индивидуальной реакцией на коллагеновый материал, так и с инъекцией как таковой.

Дизайн исследования подразумевал пять визитов с включением в исследование и скринингом по показателям включения/невключения, а также результатам аллергопробы, проведенной согласно Инструкции к материалу Коллост гель. Аллергоанамнез участниц и результат аллергопроб оценивал врач-иммунолог.

Процедуры внутрикожных инъекций Коллоста 7\% выполняли три раза с интервалом 3 недели. С целью обеспечения комфортности на кожу лица предварительно наносили анестезирующий крем Акриол Про с экспозицией 1 ч. Для инъекций использовали 2 мл материала в преднаполненных шприцах, которые предварительно нагревали в термостате при $40{ }^{\circ} \mathrm{C}$. Очищение и дезинфекцию кожи проводили с помощью 0,05\%-го раствора хлоргексидина биглюконата, в завершении процедуры на кожу лица наносили гель Траумель. Полное обследование назначали до начала инъекций, перед 
каждой процедурой (оценивая результат предыдущих) и через 3 недели после завершения курса инъекций.

Статистический анализ выполняли с помощью программы Statistica 6.0 (Statsoft; США), использовали непараметрические методы анализа. Данные представлены в виде медианы (Ме), 25-го и 75-го процентилей. Сравнение двух групп зависимых признаков проводили с использованием критерия Вилкоксона, статистически достоверными считали различия при $p<0,05$.

\section{РЕЗУЛЬТАТЫ ИССЛЕДОВАНИЯ}

\section{Анализ профиля безопасности}

В ходе исследования у всех участниц на протяжении нескольких часов или дней после процедуры наблюдались прогнозируемые местные реакции в виде покраснения кожи, незначительного отека, пальпируемых бугорков в местах инъекций. Кровоизлияния после достаточно травматичной процедуры носили в большинстве случаев характер петехий (точечных кровоизлияний), что, вероятно, связано с наличием у коллагена гемостатических свойств.

\section{Анализ эффективности}

Проведенный статистический анализ показал существенное улучшение общей клинико-эстетической картины лица, оцененной с помощью интегрального показателя, который статистически значимо снизился ( $p<0,05$; сравнение показателей после третьей процедуры с данными скрининга) (табл. 1): медиана снижения показателя составила 24,26\%. Поясним, что значение интегрального показателя тем выше, чем больший вклад в картину «возрастного лица» вносят конкретные признаки (морщины, складки, грубый рисунок кожи, телеангиэктазии и др.). Снижение показателя означает клиническое омоложение лица.

Отмечена достоверная положительная динамика в отношении глубины морщин ( $p<0,05$; сравнение показателей после третьей процедуры с данными скрининга) (табл. 1): медиана снижения суммарного показателя степени выраженности морщин по шкале MAS составила 28,57\%. Детальный анализ глубины морщин в отдельных зонах показал, что наиболее выраженная динамика выравнивания рельефа кожи отмечалась в области лба, параорбитальных областях (морщины «гусиные лапки»), нижнего века и верхней губы (рис. 1).

Отмечено существенное улучшение показателя эластичности кожи лица у 77\% участниц (табл. 2): медиана увеличения показателя в области лба составила 30,90\%, в параорбитальной - 19,10\%, в области щек - 15,75\%. Все изменения достоверны ( $p<0,05$; сравнение показателей после третьей процедуры с данными скрининга).

По данным УЗ-сканирования кожи, после завершения курса процедур у всех участниц исследования наблюдалось

Таблица 1. Показатели качества кожи на этапе скрининга и после завершения курса инъекций $(p<0,05)$

\begin{tabular}{|l|c|c|}
\hline \multicolumn{1}{|c|}{ Показатель } & Значение на этапе скрининга & Значение после завершения курса \\
\hline Интегральный показатель состояния кожи лица, баллы & $14(10 ; 17)^{\star}$ & $11,5(8 ; 13)$ \\
\hline Степень выраженности морщин (суммарный показатель по семи зонам), баллы & $12(11 ; 16)$ & $8(7 ; 11)$ \\
\hline
\end{tabular}

Примечание: * — здесь и в табл. 2 указаны значения медианы, в скобках — значения 25-го и 75-го процентилей.

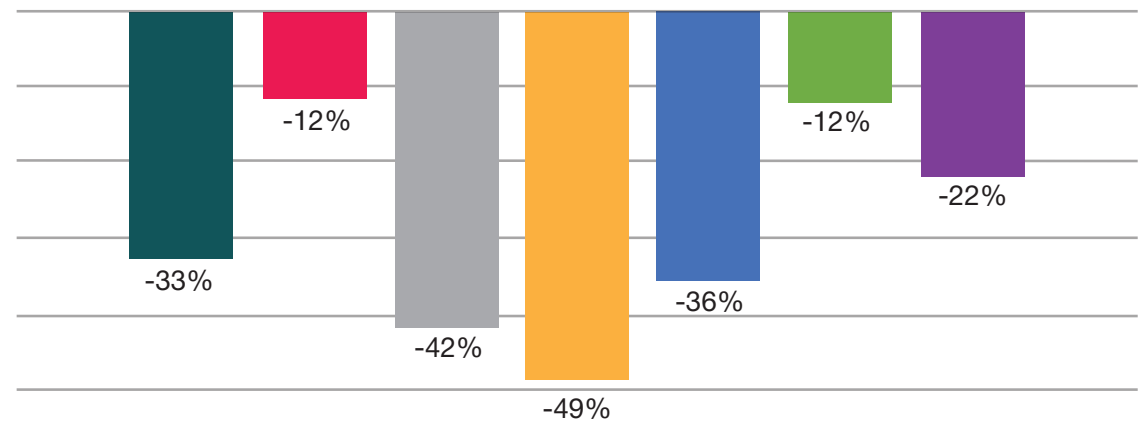

\begin{tabular}{|c|c|c|}
\hline — Лоб & Межбровная область & Параорбитальные области \\
\hline Нижнее веко & Верхняя губа & Носогубные складки \\
\hline
\end{tabular}

Рис. 1. Динамика изменения степени выраженности морщин по зонам лица (после курса лечения по сравнению с этапом скрининга)

Таблица 2. Структурно-функциональные показатели кожи на этапе скрининга и после завершения курса инъекций ( $0<0,05)$

\begin{tabular}{|c|c|c|c|c|c|c|}
\hline \multirow{3}{*}{ Показатели } & \multicolumn{3}{|c|}{ Значение на этапе скрининга } & \multicolumn{3}{|c|}{ Значение после завершения курса } \\
\hline & \multicolumn{3}{|c|}{ Зоны } & \multicolumn{3}{|c|}{ Зоны } \\
\hline & Лоб & Параорбитальная область & Щека & Лоб & Параорбитальная область & Щека \\
\hline $\begin{array}{c}\text { Толщина эпидермиса } \\
\text { (УЗИ), мм }\end{array}$ & $\begin{array}{c}0,128 \\
(0,105 ; 0,158)\end{array}$ & $\begin{array}{c}0,110 \\
(0,105 ; 0,133)\end{array}$ & $\begin{array}{c}0,132 \\
(0,108 ; 0,158)\end{array}$ & $\begin{array}{c}0,177 \\
(0,151 ; 0,192)\end{array}$ & $\begin{array}{c}0,163 \\
(0,150 ; 0,184)\end{array}$ & $\begin{array}{c}0,186 \\
(0,162 ; 0,199)\end{array}$ \\
\hline $\begin{array}{l}\text { Толщина дермы } \\
\text { (УЗИ), мм }\end{array}$ & $\begin{array}{c}1,330 \\
(1,195 ; 1,531)\end{array}$ & $\begin{array}{c}1,206 \\
(1,086 ; 1,376)\end{array}$ & $\begin{array}{c}1,592 \\
(1,256 ; 1,869)\end{array}$ & $\begin{array}{c}1,628 \\
(1,411 ; 1,790)\end{array}$ & $\begin{array}{c}1,496 \\
(1,344 ; 1,672)\end{array}$ & $\begin{array}{c}1,855 \\
(1,685 ; 2,094)\end{array}$ \\
\hline $\begin{array}{c}\text { Акустическая плотность } \\
\text { дермы (УЗИ), у. е. }\end{array}$ & $\begin{array}{c}5,102 \\
(3,741 ; 13,190)\end{array}$ & $\begin{array}{c}5,738 \\
(3,778 ; 13,470)\end{array}$ & $\begin{array}{c}5,794 \\
(2,877 ; 11,906)\end{array}$ & $\begin{array}{c}7,236 \\
(5,672 ; 13,540)\end{array}$ & $\begin{array}{c}9,071 \\
(6,026 ; 17,010)\end{array}$ & $\begin{array}{c}6,611 \\
(4,739 ; 13,230)\end{array}$ \\
\hline $\begin{array}{c}\text { Эластичность кожи } \\
\text { (кутометрия), у. е. }\end{array}$ & $\begin{array}{c}52,63 \\
(46,00 ; 61,45)\end{array}$ & $\begin{array}{c}55,08 \\
(49,85 ; 62,65)\end{array}$ & $\begin{array}{c}55,06 \\
(49,30 ; 62,00)\end{array}$ & $\begin{array}{c}66,75 \\
(56,03 ; 93,39)\end{array}$ & $\begin{array}{c}65,65 \\
(58,00 ; 74,16)\end{array}$ & $\begin{array}{c}63,25 \\
(55,50 ; 61,50)\end{array}$ \\
\hline
\end{tabular}


статистически значимое увеличение толщины эпидермиса (на 30,7-39,3\%), дермы (на 18,7-22,3\%), повышение акустической плотности дермы (на 28,7-44,5\%) во всех или нескольких областях лица (табл. 2, рис. 2 и 3) (p < 0,05; сравнение показателей после третьей процедуры с данными скрининга).

Эффективность проведенного курса инъекций материала Коллост 7\% положительно оценили 100\% участниц. По шкале GAIS половина исследуемых оценила результат как удовлетворительный с пожеланием его улучшить, при этом вторая половина была полностью удовлетворена результатом (рис. 4). С точки зрения врача, оптимальный результат достигнут у трети пациенток, у подавляющего большинства наблюдалось значительное улучшение, но не полная коррекция. У двух участниц отмечалось незначительное улучшение - как по мнению самих пациенток, так и врача-исследователя.

\section{ОБСУЖДЕНИЕ РЕЗУЛЬТАТОВ}

Проведенное клиническое исследование подтвердило эффективность применения материала Коллост 7\% В коррекции инволюционных изменений кожи. В исследовании для оценки эффективности использовали исключительно неинвазивные методы диагностики, которые позволили провести максимально полное обследование всех участниц.

Оценку общего состояния кожи, в том числе симптомов фотоповреждения/фотостарения, проводили по модифицированной схеме, основанной на критериях, предложенных Гейниц с соавт. и Alexiades-Armenakas [33, 34]. Объединенный показатель включал оценку в баллах микро- и макрорельеса кожи, ее цвета, текстуры, пигментации, сосудистого рисунка, эластоза и кератоза. После проведенного курса суммарный показатель достоверно уменьшился, при детализации стоит отметить выраженные изменения на уровне рельеса кожи (разглаживание морщин и складок) и ее цвета. У двух пациенток с тонкой кожей в области век исчезли синяки под глазами, что было воспринято крайне позитивно как самими пациентками, так и окружающими. В целом же у большинства участниц кожа приобрела розовый оттенок и более здоровый вид.

Наиболее выраженная положительная динамика глубины морщин отмечалась в области лба, параорбитальной и в области верхней губы. В этих зонах формируются поверхностные морщины, генез которых связан с атрофией/ альтерацией дермального слоя кожи [36]. Восстановление коллагенового каркаса дермы позволяет обеспечить эффективную коррекцию рельефа этих областей. В то же время для максимально эффективной коррекции глубоких складок (например, носогубных) требуется вмешательство уже на уровне подкожной жировой клетчатки.

Биомеханические свойства кожи большинство исследователей связывает с качеством волокнистого коллагенового каркаса дермы. Логично предположить, что достоверное повышение эластичности кожи участниц исследования может быть обусловлено неоколлагенезом увеличением количества зрелых волокон с неповрежденной структурой и достаточной гидрофильностью. Еще одним косвенным подтверждением реструктуризации кожи служат увеличение толщины дермы и повышение ее акустической плотности, выявленные при УЗ-сканировании. Согласно проведенным ранее исследованиям [37, 38], уменьшение толщины дермы и ее акустической плотности описывается как возрастная, ассоциированная с заболеваниями или стероидиндуцированная атрофия на фоне снижения содержания структурных фибриллярных белков. Соответственно, увеличение толщины и особенно повышение акустической плотности дермы отражают процесс накопления волокнистых структур, реструктуризацию кожи $[39,40]$. По данным проведенного нами исследования, в максимальной степени эти изменения были выражены спустя 3 недели после заключительной процедуры, что позволяет провести параллель с обсужденными выше
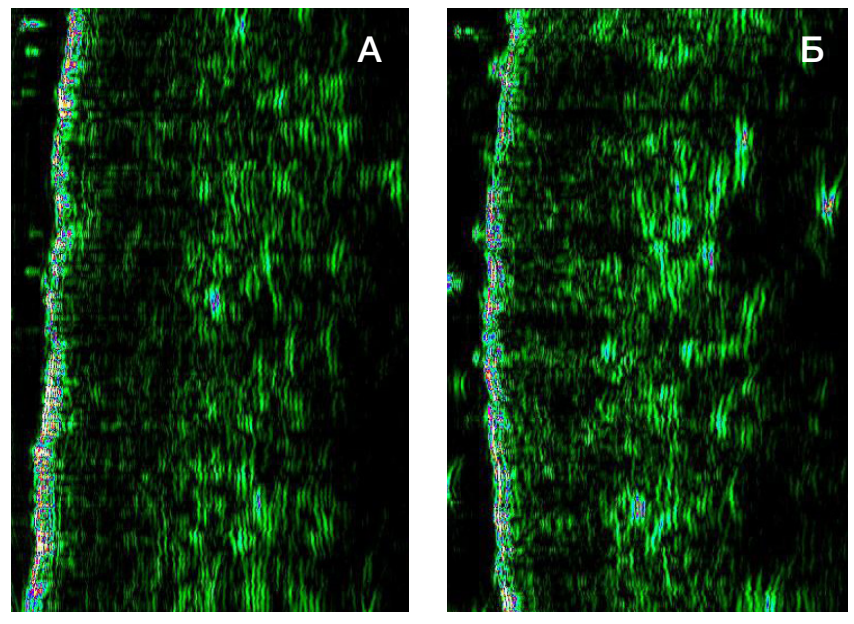

Рис. 3. УЗ-сканограммы кожи в области лба: на этапе скрининга (A), после завершения курса инъекций (Б)

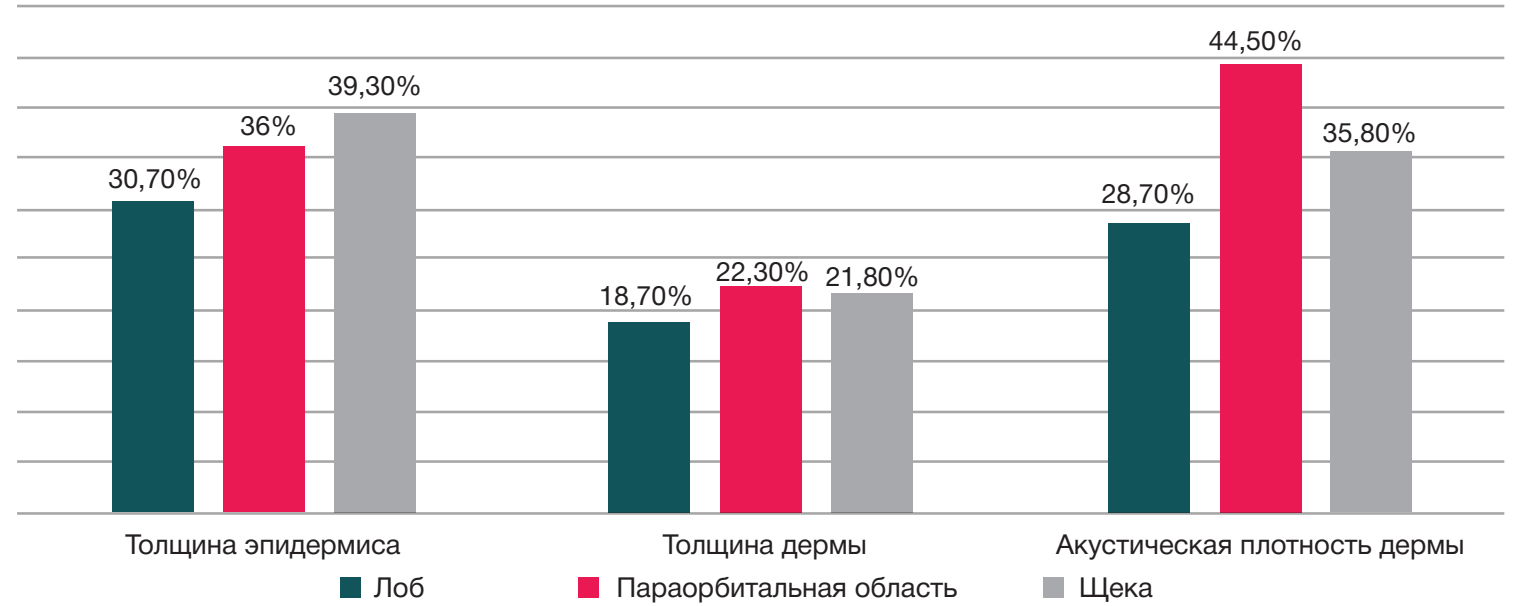

Рис. 2. Динамика структурных показателей кожи по данным УЗ-сканирования (медиана изменения после курса лечения по сравнению с этапом скрининга) 


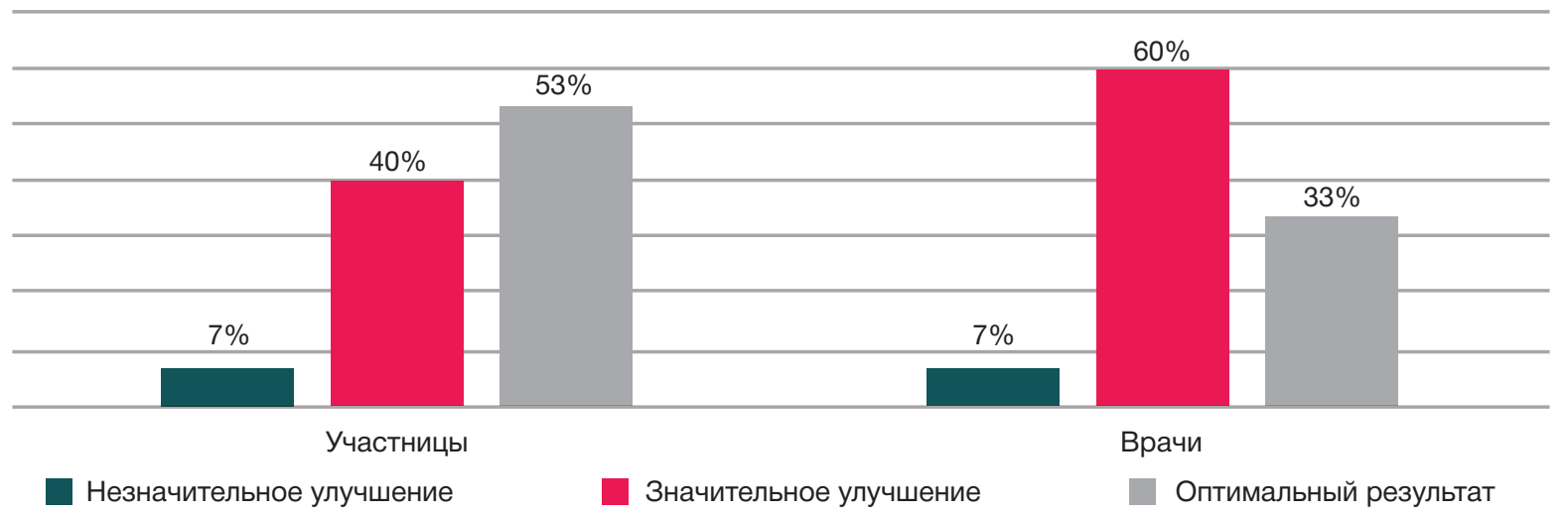

Рис. 4. Оценка эффективности курса инъекций по шкале GAIS участницами и врачами-исследователями

экспериментальными исследованиями, показавшими максимальное повышение уровня суммарного коллагена в коже через 3-4 недели после завершения инъекций Коллоста 7\% в кожу экспериментальных животных.

Следует отметить, что положительная динамика изменения биомеханических свойств кожи, ее структурные изменения, наблюдаемые после курса инъекций Коллоста 7\%, обеспечивают не только улучшение внешнего вида, но и закладывают основы профилактики развития возрастных изменений, связанных с атрофией, а также способствуют оздоровлению кожи.

\section{ВЫВОДЫ}

По данным проведенного исследования, курс внутрикожных инъекций материала Коллост 7\% позволяет улучшить эстетическую картину кожи лица с достоверной нормализацией ее цвета, уменьшением степени выраженности морщин. Положительная клиническая динамика отмечается на фоне улучшения биомеханических свойств кожи (повышение эластичности) и структурных изменений, выявленных при УЗИ, косвенно свидетельствующих о процессе ремоделирования коллагенового каркаса дермы. Таким образом, внутрикожные инъекции материала Коллост 7\% можно признать эффективным и безопасным методом эстетической коррекции. Результаты проведенного исследования, возможно, станут основой для формирования этиологически и патогенетически обоснованных протоколов комбинированной коррекции возрастных изменений кожи, включающих в себя также введение гиалуроновой и полимолочной кислот, воздействие высокоэнергетическими методами.

\section{Литература}

1. Rittié L, Fisher GJ. Natural and sun-induced aging of human skin. Cold Spring Harb Perspect Med. 2015; 5 (1): a015370.

2. Gunn DA, Rexbye H, Griffiths CE, Murray PG, Fereday A, Catt SD, et al. Why Some Women Look Young for Their Age. Tregenza T, ed. PLoS ONE. 2009; 4 (12): e8021.

3. Nkengne A, Bertin C, Stamatas GN, Giron A, Rossi A, Issachar N, et al. Influence of facial skin attributes on the perceived age of Caucasian women. J Eur Acad Dermatol Venereol. 2008: 22 (8): 982-91.

4. Hussain SH, Limthongkul B, Humphreys TR. The biomechanical properties of the skin. Dermatol Surg. 2013; 39 (2): 193-203.

5. Aziz J, Shezali H, Radzi Z, Yahya NA, Abu Kassim NH, Czernuszka J, et al. Molecular Mechanisms of Stress Responsive Changes in Collagen and Elastin Networks in Skin. Skin Pharmacol Physiol. 2016; 29 (4): 190-203.

6. Czekalla C, Schönborn KH, Döge N, Jung S, Darvin ME, Lademann J, et al. Impact of Body Site, Age, and Gender on the Collagen/Elastin Index by Noninvasive in vivo Vertical Two-Photon Microscopy. Skin Pharmacol Physiol. 2017; 30 (5): 260-7.

7. Baroni Edo R, Biondo-Simões Mde L, Auersvald A, Auersvald LA, Montemor Netto MR, Ortolan MC, et al. Influence of aging on the quality of the skin of white women: the role of collagen. Acta Cir Bras. 2012; 27 (10): 736-40.

8. Капулер О., Сельская Б., Галеева А., Камилов Ф. Метаболизм коллагеновых волокон на фоне возрастных изменений. Врач. 2015; (8): 64-9.

9. Quan T, Fisher GJ. Role of Age-Associated Alterations of the Dermal Extracellular Matrix Microenvironment in Human Skin Aging: A Mini-Review. Gerontology. 2015; 61 (5): 427-34.

10. Calleja-Agius J, Brincat M, Borg M. Skin connective tissue and ageing. Best Pract Res Clin Obstet Gynaecol. 2013; 27 (5): 727-40.

11. Danby FW. Nutrition and aging skin: sugar and glycation. Clin

Dermatol. 2010; 28 (4): 409-11.

12. Ahmed T, Nash A, Clark KE, Ghibaudo M, de Leeuw NH, Potter A, et al. Combining nano-physical and computational investigations to understand the nature of "aging" in dermal collagen. Int $J$ Nanomedicine. 2017; (12): 3303-14.

13. Moragas A, Garcia-Bonafé $M$, Sans $M$, Torán $N$, Huguet $P$, Martin-Plata C. Image analysis of dermal collagen changes during skin aging. Analyt Quant Cytol Histol. 1998; (20): 493-9.

14. El-Domyati M, Attia S, Saleh F, Brown D, Birk DE, Gasparro F, et al. Intrinsic aging VS photoaging: a comparative histopathological, immunohistochemical and ultrastructural study of skin. Exp Dermatol. 2002; (11): 398-405.

15. Yaar M, Eller MS, Gilchrest BA. Fifty years of skin aging. J Invest Dermatol. 2002; (7): 51-8.

16. Cheng W, Yan-hua R, Fang-gang N, Guo-an Z. The content and ratio of type I and III collagen in skin differ with age and injury. African J Biotechnol. 2011; 10 (13): 2524-9.

17. Fisher GJ, Varani J, Voorhees JJ. Looking older: fibroblast collapse and therapeutic implications. Arch Dermatol. 2008; 144 (5): 666-72

18. Cole MA, Quan T, Voorhees JJ, Fisher GJ. Extracellular matrix regulation of fibroblast function: redefining our perspective on skin aging. J Cell Commun Signal. 2018; 12 (1): 35-43.

19. Varani J, Spearman D, Perone P, Fligiel SE, Datta SC, Wang ZQ, et al. Inhibition of type I procollagen synthesis by damaged collagen in photoaged skin and by collagenase-degraded collagen in vitro. Am J Pathol. 2001; 158 (3): 931-42.

20. Sawamura S, Jinnin M, Kajihara I, Makino K, Aoi J, Ichihara A, et al Do scleroderma patients look young? Evaluation by using facial imaging system. Drug Discov Ther. 2017; 11 (6): 342-5.

21. Камилов Ф. Х., Сельская Б. Н., Данилова О. В., Капулер О. М. Метаболизм коллагена в коже экспериментальных животных 
при интрадермальной инъекции немодифицированного бычьего коллагена типа І. Вестник Удмуртского университета. 2017; 27 (3): 356-61.

22. Kruglikov I, Neocollagenesis in Non-Invasive Aesthetic Treatments. J Cosmet Dermatol Sci Appl. 2013; 3 (1A): 1-5.

23. Shao Y, He T, Fisher GJ, Voorhees JJ, Quan T. Molecular basis of retinol anti-ageing properties in naturally aged human skin in vivo. Int J Cosmet Sci. 2017; 39 (1): 56-65.

24. Wang F, Garza LA, Kang S, Varani J, Orringer JS, Fisher GJ, et al. In vivo stimulation of de novo collagen production caused by crosslinked hyaluronic acid dermal filler injections in photodamaged human skin. Arch Dermatol. 2007; 143 (2): 155-63.

25. Yutskovskaya $Y$, Kogan E, Leshunov E. A randomized, splitface, histomorphologic study comparing a volumetric calcium hydroxylapatite and a hyaluronic acid-based dermal filler. J Drugs Dermatol. 2014; 13 (9): 1047-52.

26. Stein $P$, Vitavska $O$, Kind $P$, Hoppe W, Wieczorek H, Schürer NY. The biological basis for poly-L-lactic acid-induced augmentation. J Dermatol Sci. 2015; 78 (1): 26-33.

27. Rao KP. Recent developments of collagen-based materials for medical applications and drug delivery systems. J Biomater Sci Polymer Ed. 1995; 7 (7): 623-45.

28. Katayama K, Armendariz-Borunda J, Raghow R, Kang AH, Seyer JM. A pentapeptide from type I procollagen promotes extracellular matrix production. J Biol Chem. 1993; 268 (14): 9941-4.

29. Maquart FX, Pasco S, Ramont L, Hornebeck W, Monboisse JC. An introduction to matrikines: extracellular matrix-derived peptides which regulate cell activity. Implication in tumor invasion. Crit Rev Oncol Hematol. 2004; 49 (3): 199-202.

30. Абоянц Р. К., Истранов Л. П., Истранова Е. В., Руденко Т. Г. Пластические материалы направленного действия на основе коллагена. Электронный сборник научных трудов «Здоровье и образование в XXI веке». 2011; (4): 184.

31. Кубанова А. А., Смольянникова В. А., Служаева Н. Г. Старение кожи и возможности коррекции препаратом коллагена Вестник дерматологии и венерологии. 2007; (5): 70-3.

32. Капулер О. М., Курамшина Е. Р. Прикладные аспекть коллагенотерапии в эстетической медицине. Экспериментальная и клиническая дерматокосметология. 2013; (5): 40-3.

33. Гейниц А. В., Киани А., Окушко С. С. Новые возможности применения глубокой и поверхностной фракционной абляции в anti-age терапии. Пластическая хирургия и косметология. 2013; (4): 625-32.

34. Alexiades-Armenakas M, Newman J, Willey A, Kilmer S, Goldberg D, Garden J, et al. Prospective multicenter clinical trial of a minimally invasive temperature-controlled bipolar fractional radiofrequency system for rhytid and laxity treatment. Dermatol Surg. 2013; 39 (2): 263-73.

35. Carruthers A, Carruthers J. A validated facial grading scale: the future of facial ageing measurement tools? J Cosmet Laser Ther. 2010; 12 (5): 235-41.

36. Tsukahara K, Tamatsu Y, Sugawara Y, Shimada K. The relationship between wrinkle depth and dermal thickness in the forehead and lateral canthal region. Arch Dermatol. 2011; 147 (7): 822-8.

37. Waller JM, Maibach HI. Age and skin structure and function, a quantitative approach (I): blood flow, pH, thickness, and ultrasound echogenicity. Skin Res Technol. 2005; (11): 221-35.

38. Jasaitiene D, Valiukeviciene S, Linkeviciute $G$, et al. Principles of high-frequency ultrasonography for investigation of skin pathology. J Eur Acad Dermatol Venereol. 2011; (25): 375-82.

39. Kozarova A, Kozar M, Minarikova E, Pappova T. Identification of the age related skin changes using high-frequency ultrasound. Acta Medica Martiniana. 2017; 17 (1): 15-20.

40. Lacarrubba F, Tedeschi A, Nardone B, Micali G. Mesotherapy for skin rejuvenation: assessment of the subepidermal lowechogenic band by ultrasound evaluation with cross-sectional B-mode scanning. Dermatol Ther. 2008; 21 (Suppl 3): 1-5.

\section{References}

1. Rittié L, Fisher GJ. Natural and sun-induced aging of human skin. Cold Spring Harb Perspect Med. 2015; 5 (1): a015370.

2. Gunn DA, Rexbye H, Griffiths CE, Murray PG, Fereday A, Catt SD, et al. Why Some Women Look Young for Their Age. Tregenza T, ed. PLoS ONE. 2009; 4 (12): e8021.

3. Nkengne A, Bertin C, Stamatas GN, Giron A, Rossi A, Issachar N et al. Influence of facial skin attributes on the perceived age of Caucasian women. J Eur Acad Dermatol Venereol. 2008: 22 (8): 982-91.

4. Hussain SH, Limthongkul B, Humphreys TR. The biomechanical properties of the skin. Dermatol Surg. 2013; 39 (2): 193-203.

5. Aziz J, Shezali H, Radzi Z, Yahya NA, Abu Kassim NH, Czernuszka J, et al. Molecular Mechanisms of Stress-Responsive Changes in Collagen and Elastin Networks in Skin. Skin Pharmacol Physiol. 2016; 29 (4): 190-203.

6. Czekalla C, Schönborn KH, Döge N, Jung S, Darvin ME, Lademann J, et al. Impact of Body Site, Age, and Gender on the Collagen/Elastin Index by Noninvasive in vivo Vertical Two-Photon Microscopy. Skin Pharmacol Physiol. 2017; 30 (5): 260-7.

7. Baroni Edo R, Biondo-Simões Mde L, Auersvald A, Auersvald LA, Montemor Netto MR, Ortolan MC, et al. Influence of aging on the quality of the skin of white women: the role of collagen. Acta Cir Bras. 2012; 27 (10): 736-40

8. Kapuler O, Selskaja B, Galeeva A, Kamilov F. Metabolizm kollagenovyh volokon na fone vozrastnyh izmenenij. Vrach. 2015; (8): 64-9.

9. Quan T, Fisher GJ. Role of Age-Associated Alterations of the Dermal Extracellular Matrix Microenvironment in Human Skin Aging: A Mini-Review. Gerontology. 2015; 61 (5): 427-34.

10. Calleja-Agius J, Brincat M, Borg M. Skin connective tissue and ageing. Best Pract Res Clin Obstet Gynaecol. 2013; 27 (5): 727-40.

11. Danby FW. Nutrition and aging skin: sugar and glycation. Clin Dermatol. 2010; 28 (4): 409-11.

12. Ahmed T, Nash A, Clark KE, Ghibaudo M, de Leeuw NH, Potter A, et al. Combining nano-physical and computational investigations to understand the nature of "aging" in dermal collagen. Int $J$ Nanomedicine. 2017; (12): 3303-14.

13. Moragas $A$, Garcia-Bonafé $M$, Sans $M$, Torán $N$, Huguet $P$, Martin-Plata C. Image analysis of dermal collagen changes during skin aging. Analyt Quant Cytol Histol. 1998; (20): 493-9.

14. El-Domyati M, Attia S, Saleh F, Brown D, Birk DE, Gasparro F, et al. Intrinsic aging VS photoaging: a comparative histopathological, immunohistochemical and ultrastructural study of skin. Exp Dermatol. 2002; (11): 398-405.

15. Yaar M, Eller MS, Gilchrest BA. Fifty years of skin aging. J Invest Dermatol. 2002; (7): 51-8.

16. Cheng W, Yan-hua R, Fang-gang N, Guo-an Z. The content and ratio of type I and III collagen in skin differ with age and injury. African J Biotechnol. 2011; 10 (13): 2524-9.

17. Fisher GJ, Varani J, Voorhees JJ. Looking older: fibroblast collapse and therapeutic implications. Arch Dermatol. 2008; 144 (5): 666-72.

18. Cole MA, Quan T, Voorhees JJ, Fisher GJ. Extracellular matrix regulation of fibroblast function: redefining our perspective on skin aging. J Cell Commun Signal. 2018; 12 (1): 35-43.

19. Varani J, Spearman D, Perone P, Fligiel SE, Datta SC, Wang ZQ, et al. Inhibition of type I procollagen synthesis by damaged collagen in photoaged skin and by collagenase-degraded collagen in vitro. Am J Pathol. 2001; 158 (3): 931-42.

20. Sawamura S, Jinnin M, Kajihara I, Makino K, Aoi J, Ichihara A, et al. Do scleroderma patients look young? Evaluation by using facial imaging system. Drug Discov Ther. 2017; 11 (6): 342-5.

21. Kamilov FH, Selskaja BN, Danilova OV, Kapuler OM. Metabolizm kollagena v kozhe jeksperimental'nyh zhivotnyh pri intradermal'noj in'ekcii nemodificirovannogo bych'ego kollagena tipa I. Vestnik Udmurdskogo universiteta. 2017; 27 (3): 356-61. 
22. Kruglikov I. Neocollagenesis in Non-Invasive Aesthetic Treatments. J Cosmet Dermatol Sci Appl. 2013; 3 (1A): 1-5.

23. Shao Y, He T, Fisher GJ, Voorhees JJ, Quan T. Molecular basis of retinol anti-ageing properties in naturally aged human skin in vivo. Int J Cosmet Sci. 2017; 39 (1): 56-65.

24. Wang F, Garza LA, Kang S, Varani J, Orringer JS, Fisher GJ, et al. In vivo stimulation of de novo collagen production caused by crosslinked hyaluronic acid dermal filler injections in photodamaged human skin. Arch Dermatol. 2007; 143 (2): 155-63.

25. Yutskovskaya Y, Kogan E, Leshunov E. A randomized, splitface, histomorphologic study comparing a volumetric calcium hydroxylapatite and a hyaluronic acid-based dermal filler. J Drugs Dermatol. 2014; 13 (9): 1047-52.

26. Stein $P$, Vitavska $O$, Kind $P$, Hoppe W, Wieczorek H, Schürer NY The biological basis for poly-L-lactic acid-induced augmentation. J Dermatol Sci. 2015; 78 (1): 26-33.

27. Rao KP. Recent developments of collagen-based materials for medical applications and drug delivery systems. J Biomater Sci Polymer Ed. 1995; 7 (7): 623-45.

28. Katayama K, Armendariz-Borunda J, Raghow R, Kang AH, Seyer JM. A pentapeptide from type I procollagen promotes extracellular matrix production. J Biol Chem. 1993; 268 (14): 9941-4.

29. Maquart FX, Pasco S, Ramont L, Hornebeck W, Monboisse JC. An introduction to matrikines: extracellular matrix-derived peptides which regulate cell activity. Implication in tumor invasion. Crit Rev Oncol Hematol. 2004; 49 (3): 199-202.

30. Abojanc RK, Istranov LP, Istranova EV, Rudenko TG. Plasticheskie materialy napravlennogo dejstvija na osnove kollagena. Jelektronnyj sbornik nauchnyh trudov "Zdorov'e i obrazovanie v XXI veke". 2011; (4): 184.

31. Kubanova AA, Smoljannikova VA, Sluzhaeva NG. Starenie kozhi i vozmozhnosti korrekcii preparatom kollagena. Vestnik dermatologii i venerologii. 2007; (5): 70-3.
32. Kapuler OM, Kuramshina ER. Prikladnye aspekty kollagenoterapii $\checkmark$ jesteticheskoj medicine. Jeksperimental'naja i klinicheskaja dermatokosmetologija. 2013; (5): 40-3.

33. Gejnic AV, Kiani A, Okushko SS. Novye vozmozhnosti primenenija glubokoj i poverhnostnoj frakcionnoj abljacii $v$ anti-age terapii. Plasticheskaja hirurgija i kosmetologija. 2013; (4): 625-32.

34. Alexiades-Armenakas M, Newman J, Willey A, Kilmer S, Goldberg D, Garden J, et al. Prospective multicenter clinical trial of a minimally invasive temperature-controlled bipolar fractional radiofrequency system for rhytid and laxity treatment. Dermatol Surg. 2013; 39 (2): 263-73.

35. Carruthers A, Carruthers J. A validated facial grading scale: the future of facial ageing measurement tools? J Cosmet Laser Ther. 2010; 12 (5): 235-41.

36. Tsukahara K, Tamatsu Y, Sugawara Y, Shimada K. The relationship between wrinkle depth and dermal thickness in the forehead and lateral canthal region. Arch Dermatol. 2011; 147 (7): 822-8.

37. Waller JM, Maibach HI. Age and skin structure and function, a quantitative approach (I): blood flow, $\mathrm{pH}$, thickness, and ultrasound echogenicity. Skin Res Technol. 2005; (11): 221-35.

38. Jasaitiene D, Valiukeviciene $S$, Linkeviciute $G$, et al. Principles of high-frequency ultrasonography for investigation of skin pathology. J Eur Acad Dermatol Venereol. 2011; (25): 375-82.

39. Kozarova A, Kozar M, Minarikova E, Pappova T. Identification of the age related skin changes using high-frequency ultrasound. Acta Medica Martiniana. 2017; 17 (1): 15-20.

40. Lacarrubba F, Tedeschi A, Nardone B, Micali G. Mesotherapy for skin rejuvenation: assessment of the subepidermal lowechogenic band by ultrasound evaluation with cross-sectional B-mode scanning. Dermatol Ther. 2008; 21 (Suppl 3): 1-5. 